\title{
De la "revisión de vida" al despertar del compromiso cristiano contestatario. Las ramas especializadas de Acción Católica en Bahía Blanca (Argentina), 1967-1975
}

\author{
Virgínia Lorena Dominella*
}

\section{Resumen}

En este trabajo, exploramos las singularidades del método de la "revisión de vida" aplicado en la Juventud Universitaria Católica, la Juventud Obrera Católica y la Juventud Estudiantil Católica de Bahía Blanca (Argentina) en el período 1967-1975, y su vinculación con las trayectorias militantes. Nos preguntamos ¿qué significación tuvo la reflexión al ritmo de "Ver, Juzgar y Actuar" en la vivencia religiosa de los jóvenes bahienses? ¿En qué medida favoreció el discernimiento de los procesos sociales, económicos y políticos del momento, y a partir de aquél, los impulsó a una intervención transformadora? Para este abordaje, optamos por una metodología cualitativa y, en este sentido, por la utilización de diversas estrategias, desde entrevistas en profundidad hasta el análisis de distintas fuentes escritas.

Palabras clave: Revisión de vida - Acción Católica especializada - compromiso cristianoBahía Blanca - años '70

\section{Da "revisão da vida" ao despertar do compromisso cristão contestatório. Os ramos especializados da Ação Católica em Bahia Blanca (Argentina), 1967-1975}

\section{Resumo}

Neste artigo, vamos explorar a singularidade do método de "revisão de vida" aplicado à Juventud Universitaria Católica, à Juventud Obrera Católica e à Juventud Estudiantil Católica da cidade de Bahía Blanca (Argentina), no período 1967-1975, e suas ligações com as

\footnotetext{
* Profesora y Licenciada en Historia por la Universidad Nacional del Sur, Doctora en Historia por la Universidad Nacional de La Plata (Argentina), y becaria post-doctoral del Consejo Nacional de Investigaciones Científicas y Técnicas.

E-mail: v_dominella@yahoo.com.ar
} 
trajetórias militantes. Perguntamo-nos: que significação teve a reflexão "Ver, Julgar e Agir" na vivencia religiosa dos jovens bahienses? Em que medida favoreceu o discernimento dos processos sociais, econômicos e políticos do momento, e a partir daí, o ímpeto pela intervenção transformadora? Para esta abordagem, optamos por uma metodologia qualitativa usando diferentes estratégias, tais como entrevistas em profundidade e análise de diversas fontes escritas.

Palavras-chave: Revisão da vida - Ação Católica especializada - compromisso cristão

- Bahia Blanca - anos 70

\title{
From the Life Rewiew method to the christian commitment in social change. Specialised Catholic Action movements in Bahía Blanca (Argentina) between 1967 and 1975
}

\begin{abstract}
This article explores the specific aspects of Life Rewiew method applied by the Juventud Universitaria Católica, the Juventud Obrera Católica and the Juventud Estudiantil Católica in Bahía Blanca (Argentina), between 1967 and 1975, as well as its links with the militant itineraries. In this sense, it tries to reflect upon the following questions: What is the significance of this christian reflection for the religious experience of the youth? To what extent this method had promote the awareness of social, economical or political problems and, as a result, had encourage these people to involve in social change? The approach that has been chosen is that of a qualitative methodology as well as a selected range of strategies, from in-depth interviews to the analysis of different written sources. Key words: Life Review method - specialised Catholic Action - christian commitmentBahía Blanca - 1970s
\end{abstract}

\section{Introducción}

En este trabajo", exploramos las singularidades del método de la "revisión de vida" aplicado en la Juventud Universitaria Católica (JUC), la Juventud Obrera Católica (JOC) y la Juventud Estudiantil Católica (JEC) de Bahía Blanca $^{2}$ en el período 1967-1975, atendiendo a cómo se llevó a cabo, sobre qué tipo de cuestiones giraba y con qué dificultades se enfrentaba su ejercicio, así como su vinculación con las trayectorias militantes. En este sentido, nos preguntamos ¿qué significación tuvo la reflexión al ritmo de "Ver, Juzgar y

\footnotetext{
1 Se inscribe en mi investigación doctoral, financiada por el CONICET (2010-2015) y plasmada en mi tesis. Agradezco los comentarios y las sugerencias de Aldo Ameigeiras, que han enriquecido este trabajo.

2 Ciudad ubicada a $700 \mathrm{~km}$ al sur de la provincia de Buenos Aires. Fundada en 1828, en la década de 1970, rondaba los 182 mil habitantes y tenía gran relevancia a nivel regional desde el punto de vista económico -polo de desarrollo más importante del sur argentino-, militar -sede de diversas unidades militares- y cultural -asiento de distintas instituciones de educación superior.
} 
Actuar" en términos de la vivencia religiosa de los jóvenes bahienses? ¿En qué medida favoreció el discernimiento de los procesos sociales, económicos y políticos del momento, y a partir de aquél, los impulsó a una intervención transformadora? Así, intentamos brindar un aporte al estudio de las características de la "revisión de vida" y sus implicancias no sólo en la vida cotidiana de los militantes, sino también en el compromiso cristiano. En efecto, a pesar de su relevancia como instancia de transformación personal no ha sido suficientemente considerada. De este modo, procuramos aportar nuevas claves para comprender el proceso de acercamiento a la acción social y política protagonizado por los jucistas, jecistas y jocistas en esos años.

Para este abordaje, optamos por una metodología cualitativa y, en este sentido, por la utilización de diversas estrategias, desde entrevistas en profundidad (19 a integrantes de la JUC, 18 de la JEC, a 12 de la JOC, y al sacerdote asesor, realizadas entre marzo de 2008 y mayo de 2013) hasta el análisis de distintas fuentes escritas, que incluyen publicaciones católicas oficiales (especialmente las editadas por el Secretariado Latinoamericano (SLA) del Movimiento Internacional de Estudiantes Católicos- Juventud Estudiantil Católica Internacional (MIEC-JECI) ${ }^{3}$-como Boletín Spes, JEC Boletín Secundario, Servicio de Documentación -, volantes y apuntes personales, apelando a estrategias de triangulación para lograr una comprensión en profundidad del problema en cuestión.

Los protagonistas de esta historia se identificaban con el aggiornamento eclesial gestado durante la década de 1950, legitimado con los pontificados de Juan XXIII y Pablo VI, el Concilio Vaticano II (1962-1965), la II Conferencia General del Episcopado Latinoamericano reunido en Medellín (1968) y la II Asamblea Extraordinaria del Episcopado Argentino en San Miguel (1969). En este marco, los actores se integraron a un amplio movimiento social-religioso que, siguiendo a Löwy (1999), denominamos catolicismo liberacionista. Este movimiento, del cual la teología de la liberación es su expresión intelectual, incluye tanto la cultura religiosa como la red social, la fe y la praxis, y se caracteriza por una serie de principios básicos, a saber: la lucha contra los nuevos ídolos de la muerte (el mercado, la civilización occidental y cristiana, etc.); la liberación humana histórica como anticipación de la salvación final; la crítica

\footnotetext{
3 Era la convergencia en América Latina de dos movimientos especializados internacionales que trabajaban con estudiantes y se unificaron a partir de 1966 en función de compartir una misma línea teológico-pastoral: la asunción del "compromiso con la liberación de América Latina” (“Aproximación a la realidad latinoamericana. Iglesia-Movimiento", Spes, 19, octubre 1972).
} 
a la teología dualista tradicional y una nueva lectura de la Biblia; una aguda denuncia del capitalismo como pecado estructural; el recurso al marxismo como instrumento social-analítico; la opción por los pobres y la solidaridad con su lucha de autoliberación.

Sin negar las transformaciones que experimentó el catolicismo en esos años, es necesario adoptar una mirada de largo plazo y ligar esta corriente liberacionista con una "matriz común": el catolicismo integral. Este fenómeno, cuyo desarrollo comenzó a hacerse visible a partir de la década de 1920, constituía la respuesta del catolicismo argentino al avance secularizador del liberalismo y el socialismo, que intentaba constreñirlo al ámbito privado. Así, buscó integrar las instancias de lo social, lo político, lo religioso, lo público y lo privado, y avanzar sobre la sociedad y el Estado (MALLIMACI, 1992).

A partir de esta matriz integral y de los cambios que supuso el aggiornamento eclesial en la concepción de la Iglesia y de su relación con el mundo, muchos cristianos liberacionistas abrazaron la idea de compromiso y asumieron diversas formas de intervención pública con la intención de participar en la transformación de la realidad en un contexto local, nacional y latinoamericano marcado por la efervescencia social y política. Como ocurrió en otros puntos

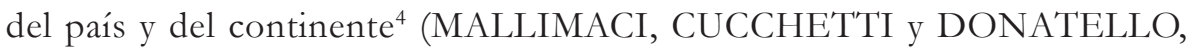
2006; DONATELLO, 2010; DONATELLO y CATTOGIO, 2011), estos jóvenes asumieron la participación en tareas pastorales, el trabajo social y villero, la militancia universitaria y en la escuela secundaria, la organización sindical, y el activismo en agrupaciones políticas y político-militares. Éstas eran de distintas vertientes de la izquierda peronista ${ }^{5}$-Peronismo de Base (PB), Juventud Peronista (JP), Juventud Trabajadora Peronista (JTP), Juventud Universitaria Peronista (JUP), Unión de Estudiantes Secundarios (UES),

\footnotetext{
4 "Una experiencia de evangelización en el medio estudiantil", Spes, 29, pascua de 1976. "Estudio de la JEC latinoamericana", JEC Boletín Secundario, 14, agosto de 1970.

5 El peronismo es un amplio y heterogéneo movimiento político surgido en 1945 en la Argentina. Su líder, Juan Domingo Perón, fue presidente de la nación en dos mandatos consecutivos entre 1946 y 1955, año en que fue derrocado por un golpe de estado -liderado por Eduardo Lonardi y Pedro Eugenio Aramburu-. Su gobierno, de carácter populista, se caracterizó por la inclusión de los sectores populares en el plano social, político y simbólico. Luego de un largo exilio de 18 años, volvió al país y al poder - gobiernos de Héctor Cámpora (mayo-julio de 1973) y de Perón (octubre de 1973-junio de 1974) - en un contexto marcado por profundos conflictos sociales y políticos, así como por enfrentamientos cada vez más violentos entre las distintas fracciones del movimiento peronista. Después de su muerte, en julio del '74, su mujer, la vicepresidenta Isabel Perón, lo sucedió en el gobierno, consolidando el avance de la derecha peronista y del terror paraestatal.
} 
Montoneros- y no peronista -Partido Comunista Revolucionario (PCR) ${ }^{6}$ o el Partido Revolucionario de los Trabajadores-Ejército Revolucionario del Pueblo (PRT-ERP) ${ }^{7}$ -

La JUC bahiense comenzó a constituirse en 1967, como un intento de recrear con nuevos integrantes y asesores, una experiencia anterior que se encontraba desarticulada, y llegó a agrupar unos 40 jóvenes que estudiaban en la Universidad Nacional del Sur (UNS) o en diversos institutos terciarios. La JOC se formó en 1968 con un pequeño grupo de trabajadores, en su mayoría empleados de comercio, que vivían en el barrio Sánchez Elía o aledaños, y participaban en las actividades de la capilla Nuestra Señora del Carmen. Con el tiempo, llegaron a sumar 16 integrantes. La JEC, constituida hacia mediados de 1972, reunió a 30 estudiantes secundarios que asistían a diferentes escuelas públicas y privadas de la ciudad y provenían del movimiento Guía-Scout del centro pastoral La Pequeña Obra o de los grupos juveniles de Nuestra Señora del Carmen.

Tanto las ramas estudiantiles como la obrera funcionaban divididas en equipos de 6-7 personas que se reunían semanalmente, con la compañía de un sacerdote asesor, a reflexionar mediante el ritmo de "Ver, Juzgar y Actuar". Esta práctica se encuadraba en la metodología de la "revisión de vida" que comenzó a usarse en la Acción Católica, especialmente en los orígenes de la JOC. Desde sus raíces belgas, se convirtió en una de las notas identitarias de dicho movimiento. Más tarde, la encíclica Mater et Magista del Papa Juan XXIII constituyó la "revisión de vida" en el modo fundamental de analizar la realidad enmarcada en la Doctrina Social de la Iglesia. El primer paso consistía en analizar la situación social, económica y política, identificando sus causas y consecuencias. Le seguía confrontar los datos históricos con el Evangelio, es decir, interpretar su sentido teológico y juzgarlos reflexivamente a la luz de "la positividad cristiana". Por último, se buscaba discernir crítica y

\footnotetext{
El PCR surgió a principios de 1968, a partir de ex militantes del Partido Comunista Argentino que denunciaron que el "revisionismo" del partido había traicionado la política revolucionaria marxista-leninista. Simpatizaban con el maoísmo y estaban a favor de una estrategia insurreccionalista (GORDILLO, 2003).

7 El PRT fue fundado en 1965 luego de la unión de dos organizaciones: Palabra Obrera - de tendencia trotskista, nacida en las urbes industriales- y el Frente Revolucionario Indoamericano y Popular -nacionalista y antiimperialista, abocado a las problemáticas de los trabajadores del norte argentino. En el V Congreso partidario, celebrado en 1970, un sector del PRT conocido como PRT El Combatiente fundó el ERP (SEOANE, 1993). Para un mayor desarrollo del PRT-ERP en Bahía Blanca, véase GIMÉNEZ, 2008.
} 
prácticamente qué pautas de acción surgían para modificar la realidad social según los criterios evangélicos (SCANNONE, 1987).

En los grupos bahienses, la "revisión de vida" fue introducida por los asesores José "Pepe" Zamorano (1932-2012) y Emilio Flores (1937) ${ }^{8}$. Oriundos de España, llegaron a la Argentina en 1966 y a Bahía Blanca en 1967ª a través de la Obra de Cooperación Sacerdotal Hispanoamericana (OCSHA), un organismo creado a fines de los años cuarenta y patrocinado por el episcopado español, que institucionalizaba el envío de misioneros diocesanos durante un tiempo a América Latina para fortalecer las Iglesias con pocas vocaciones sacerdotales. Para ello, entre 1957 y 1961 completaron su formación en el Seminario Hispanoamericano de Madrid, que se encontraba en la corriente de renovación eclesial. Allí tuvieron un contacto indirecto con los movimientos especializados de juventud a través de su director espiritual -el Padre Fernando Urbina-, quien acompañaba a la JOC y tenía una estrecha ligazón con las bases trabajadoras, y de algunos profesores, que se desempeñaban como asesores nacionales de la JUC y de la JOC. Por otra parte, los misioneros formaron equipos por destino, donde ejercitaron y asumieron la metodología de la "revisión de vida" desde su realidad de estudio.

Debe tenerse en cuenta que desde comienzos de los años 1950, en España, la Acción Católica obrera experimentó una transformación, que luego se difundió y extendió a las otras ramas, y estaba marcada por el valor del "compromiso temporal" como tarea ineludible. En este proceso, el método de la "revisión de vida" ocupó un rol central, en cuanto favoreció el reconocimiento de los problemas reales, el descubrimiento en ellos de los principios evangélicos y el diálogo con otras militancias fuera de las organizaciones católicas, formando directa o indirectamente a los jóvenes en actitudes críticas y democráticas (MONTERO GARCÍA, 2006).

\footnotetext{
8 La reflexión comunitaria de la JUC anterior tenía una impronta fundamentalmente "intelectual" y "teórica" y si bien se fue orientando cada vez más a la acción, no consistía en la "revisión de vida" tal y como fue ejercitada en los nuevos equipos jucistas a partir de 1967. (Entrevista a Ángel, Buenos Aires, 8/10/2009. Integró la primera JUC bahiense (1962-1966) y la nueva JUC (1967-1974). Militó en la UNS en la Liga Humanista, el Movimiento Universitario Personalista (1965), el PRT (1966-1967), la Agrupación Universitaria de Acción Liberadora (AUDAL, ligada al PCR) y la JUP. Los nombres de los entrevistados fueron cambiados, a excepción de las figuras públicas cuya identificación resulta inevitable, obedeciendo al pedido de los actores.

9 Durante su permanencia en la ciudad (Flores, hasta 1971, y Zamorano, hasta 1975), estuvieron a cargo de Nuestra Señora del Carmen, acompañaron a los Scouts y Guías de La Pequeña Obra y fueron asesores de la JUC. Zamorano también asesoró a la JOC y a la JEC e integró el Movimiento de Sacerdotes para el Tercer Mundo (MSTM).
} 
En los equipos locales el método era apuntalado por el MIEC-JECI, al que pertenecían la JUC y la JEC. Éste ofrecía instancias y materiales de formación como respuesta a la necesidad de los grupos de ampliar el marco teórico de la "revisión de vida" el Encuentro del Cono Sur en Córdoba en 1971, al que los participantes no sólo debían acercar una evaluación de la experiencia metodológica de cada sitio, sino también leer una serie de documentos del Servicio de Documentación referidos a la pedagogía de la pastoral universitaria ${ }^{11}$.

Asimismo, los encuentros periódicos del movimiento a nivel mundial, latinoamericano, nacional y local seguían el ritmo de "Ver, Juzgar y Actuar". Así, tanto el Comité Latinoamericano como la Asamblea Interfederal del MIEC y la Sesión Mundial de la JECI eran consideradas "una gran revisión de vida"12, donde el sujeto de la misma era el movimiento: partiendo de las distintas experiencias en el medio estudiantil, a la luz de las cuales se buscaba verse a sí misma como movimiento de Iglesia, para juzgar el grado de fidelidad asumido con la realidad "donde se manifiesta el Señor", y poder aproximarse a las acciones que exigían "la construcción del mundo nuevo, del hombre nuevo y de la nueva Iglesia"13.

\section{Una manera de "hacer teología"}

La metodología que vertebraba la reflexión de la JUC, la JEC y la JOC es también un aspecto central desde el cual considerar la influencia de los nuevos aportes teológicos. A partir de esta pertenencia al MIEC-JECI los estudiantes católicos bahienses se vieron marcados por los teólogos liberacionistas, tanto en su formación como en sus opciones de militancia. Algunos de estos referentes -como Gustavo Gutiérrez- eran asesores del movimiento y sus elaboraciones teológicas tenían esas experiencias pastorales como punto de partida ${ }^{14}$. Además, estos especialistas escribían en las publicaciones del Secretariado o participaban de los encuentros.

\footnotetext{
10 "Seminario Fe y Política", Spes, 22-23, enero 1974.

11 "Encuentro del Cono Sur, Carta Circular", Spes, 11, octubre 1970.

12 "Noticias del SLA", Spes, 19, octubre 1972. "Aproximación a la realidad latinoamericana. Iglesia-Movimiento", Spes, 19, octubre 1972. "Comité Latinoamericano de la JECI”, JEC Boletin Secundario, 14, agosto 1970.

13 “Sesión Mundial 70", JEC Boletín Secundario, 10, junio 1969.

14 Entrevista a Mónica, Buenos Aires, 9/11/2011 y a José Zamorano, Moreno, 2/9/2011. Mónica también recordaba a Rolando Muñoz, Jon Sobrino o Ignacio Ellacuría. Fue dirigente Scout (1971-1974), integrante de la JEC y de la UES (1972-1975).
} 
Pero la "pedagogía" -como se la llamaba entonces- de la "revisión de vida" marcó a los grupos bahienses incluso años antes que Gutiérrez sistematizara en su libro las reflexiones teológicas latinoamericanas de los años sesenta. En este sentido, los movimientos especializados de juventud, anticipaban uno de los ejes de la teología de la liberación. Podría decirse que los grupos de reflexión cristianos, en cuanto se proponían pensar su fe en el contexto de "opresión" y su historia concreta desde la fe, "hacían teología", aunque en una forma y un lenguaje distinto al de los teólogos profesionales. En este sentido, Julio afirmaba: "nosotros deciamos que la teología se hacía a partir de la experiencia y la reflexión"15.

Asimismo, esa reflexión "sobre la realidad a la luz del Evangelio" se fue enriqueciendo en esos años, por un lado, con los desarrollos de los teólogos liberacionistas, que lejos de definirse como "intelectuales de escritorio", lo hacían como agentes que participaban del "caminar del pueblo" (BOFF, 1990); y, por el otro, de los sacerdotes que acompañaban a los jóvenes, quienes, inspirados en el Concilio y en Medellín, fueron modelando su postura teológica y eclesial a partir de su acción pastoral y los lazos tejidos entre ellos.

En efecto, desde la óptica liberacionista, existían diversos planos de elaboración teológica que, lejos de estar aislados, frecuentemente progresaban de un modo integrado (BOFF, 1990). En palabras de Scannone (1987), el discurso de la revisión de vida, el profético y el pastoral constituían un primer paso de discernimiento crítico a la luz de la Palabra. Así, la teología de la liberación era concebida como un fenómeno cultural y eclesial complejo que no se limitaba a los teólogos, sino que recorría todo el cuerpo eclesial, y estaba vivo también en un nivel pastoral (en la reflexión de los obispos, sacerdotes, religiosas y otros agentes pastorales) y en otro popular (en la reflexión teológica en clave liberadora que tenía lugar en las bases de la Iglesia de forma anónima y colectiva, oral y sacramental, crítica y profética), aunque no se llamara "teología". En el primer plano, la teología era producida por teólogos de profesión, de una manera más elaborada y rigurosa; estaba guiada por una lógica de tipo científico (metódica, sistemática y dinámica); utilizaba la mediación socio-analítica, la hermenéutica y la práctica; su producción se materializaba en conferencias, libros y artículos. La teología de la liberación pastoral era más orgánica en relación a la praxis; estaba guiada por una lógica de acción concreta, profética; utilizaba el método del "Ver, Juzgar y Obrar"; y se expresaba en discusiones y documentos pastorales. En el nivel popular, la

15 Entrevista a Julio, Bahía Blanca, 22/5/2010. Integró la JUC (1968-1975), tuvo militancia universitaria en el PB (1969-1973) y eclesial (desde 1972). 
teología era más difusa y espontánea; seguía la lógica de la vida (oral, gestual, sacramental); era elaborada a partir de la confrontación del Evangelio y la vida; y se materializaba en comentarios y celebraciones (BOFF, 1990). Desde esta perspectiva, entonces, una sabiduría teologal no científica era articulada por "quienes se convierten al pobre, en cuanto ellos son sujeto comunitario de una praxis evangélicamente liberadora y de la inteligencia de la fe que la acompaña” (SCANNONE, 1987, p. 45).

\section{"Ver, Juzgar y Actuar"}

Según recuerdan los protagonistas, el "Ver" suponía revisar los acontecimientos de la semana vinculados a la realidad en la que estaban inmersos los militantes, describirlos, interpretarlos, relacionarlos con otros. No había un temario prefijado sino que los jóvenes acercaban al encuentro las situaciones a discutir, siendo sus propias prácticas las que marcaban la agenda de la "revisión de vida".

El "Juzgar" implicaba el ejercicio de pensar qué hubiera hecho Jesús en una situación similar, qué podía decirles el Evangelio "aquí y ahora”. En este camino, la Biblia y la vida se vinculaban de dos maneras complementarias. Al decir de "Pepe": "la Palabra ilumina [la realidad] y la realidad va como haciendo actual la Palabra"'16. En general, eran los asesores quienes se encargaban de guiar a los jóvenes en esa búsqueda de relaciones entre el texto bíblico y el quehacer diario.

Finalmente, la reflexión se orientaba a buscar formas de compromiso concretas que, de manera individual o colectiva, y en el marco de los espacios de pertenencia de los militantes, incidieran en la cuestión planteada. En palabras de Patricia, "transformar la realidad desde el lugar donde a vos te tocaba, si era la escuela, si era el trabajo..." "17. Al mismo tiempo, el cambio incluía una dimensión personal. En este sentido, para los militantes, el ejemplo de Cristo lo interpelaba a traducir las palabras en gestos. La cuestión de la acción estaba así implícita en toda la reflexión comunitaria aunque se explicitaba en este tercer momento; le daba sentido a todo el proceso, convirtiéndose a la vez en su punto de partida y de llegada. Eduardo decía: "era la reflexión sobre nuestra experiencia para volver a proyectarnos" $"$.

16 Entrevista a José Zamorano, Moreno, 19/9/2009.

17 Entrevista a Patricia, Bahía Blanca, 19/5/2008. Dirigente del movimiento Guías, integrante de la JUC, tuvo militancia social (como maestra de la escuela Nuestra Señora de la Paz) y política (JP) en el barrio periférico de Villa Nocito en 1973-1974.

18 Entrevista a Eduardo, Bahía Blanca, 21/3/2008. Integró la JUC (1968-1975), fue miembro del SLA (1971 y 1972), y militante en la UNS de los Grupos Socialistas (ligados al PRT), AUDAL (1968-1970) y JUP (1973-1974). 
La "revisión de vida", por lo que llevaba de ejercicio reflexivo y analítico, de introspección, de exposición de la propia historia, y de modo novedoso de vincular el mensaje cristiano con los hechos de la vida corriente, no resultó sencilla de comprender e incorporar. En general, los jóvenes no estaban habituados a concretar una reflexión en torno a cuestiones específicas - "bajar a tierra"19, en palabras de Paloma-; hacerlo según los pasos del método; expresarse en un contexto grupal; interpretar la realidad estudiantil o laboral; analizar documentos; leer hechos sociales y políticos desde la óptica cristiana, encontrándole su sentido trascendente, y, a la vez, leer la Biblia desde el compromiso de los militantes en sus propios ámbitos y desde una práctica comunitaria de la fe; sacar conclusiones o llevar la reflexión a la acción.

Sin embargo, en el transcurso de los encuentros y con la ayuda del asesor, los jóvenes adquirieron experiencia en el uso de esta pedagogía. Al respecto, Manuel afirmaba: "el metodólogo nuestro fue Pepe" renovación de los agentes religiosos no sólo fue teológica, doctrinaria y pastoral sino que también se tradujo en su compromiso y testimonio personal -un tipo de relación que era parte de una pedagogía de evangelización de los miembros de la Iglesia-. Al mismo tiempo, los militantes asumieron cada vez mayor protagonismo y autonomía respecto del sacerdote, pudiendo incluso prescindir de su presencia en las reuniones, aún en el segundo paso de la reflexión, donde el asesor tenía un papel importante ${ }^{21}$.

Ahora bien, ¿sobre qué cuestiones versaba el "Ver”? ¿En qué tipo de problemas, espacios, dimensiones de la realidad buscaba "Actuar"? En la JOC, los hechos vinculados al medio laboral ocupaban un lugar central. Así, se ponía en común lo vivido en la relación con el patrón y los compañeros, las condiciones de trabajo, las luchas y conflictos laborales, o la participación sindical. Por su parte, los jucistas abordaban las problemáticas cotidianas que se presentaban en la universidad o los institutos terciarios, mientras que los jecistas se centraban en las escuelas y las cuestiones inherentes al mundo de los estudiantes secundarios.

19 Entrevista a Paloma, vía skype, 11/2/2013. Integró la JOC (1968-1975), fue docente en Villa Nocito, catequista y, entre 1972 y 1976, militó en el PB.

20 Entrevista a Manuel y Nancy, Neuquén, 21/3/2013. Manuel integró JUC, militó en el PB y en la JUP, y formó parte del SLA en Lima (fines de 1973 y mediados de 1976).

21 Entrevista a Mirta y Jorge, Bahía Blanca, 14/7/2012; a Inés, Bahía Blanca, 18/6/2011; y a Manuel y Nancy, Neuquén, 21/3/2013. Mirta integró la JOC (1968 y 1975), fue catequista, tuvo militancia gremial y política en el PB. Jorge integró la JOC (1972 y 1975), tuvo trabajo parroquial, militancia gremial y política en el PB. Inés fue catequista en Nuestra Señora del Carmen, integrante de la JEC (1972 y 1975), y militó en la UES. Nancy integró la JUC, fue dirigente Guía y trabajó en el SLA con Manuel. 
Pero no se trataba sólo de comentar las situaciones laborales o estudiantiles, sino, fundamentalmente, de revisar la acción de los militantes en los espacios donde se desempeñaban, esto es, de qué manera, desde su perspectiva, "Ilevaban el Evangelio"22 a su medio, comprometiéndose en lo que entendían como la construcción de un orden social más justo. Aquí, la intervención en el propio ambiente variaba en función del tipo de oficio, empleo o profesión, de la existencia o no de participación gremial ligada a aquél, de la idiosincrasia de cada institución educativa y de la variedad de carreras universitarias. Por otra parte, incluso en el mismo grupo, los compromisos de los militantes eran diversos. De esta manera, se pensaba la participación en el scoutismo, en la comunidad religiosa, en el barrio o la villa, en el gremio, en la política estudiantil o en las organizaciones político-militares. Esto imprimía a la reflexión una amplia gama de problemas. Así, por ejemplo, mientras los jóvenes que desarrollaban un activismo político en la UNS acercaban a las reuniones las situaciones que se les presentaban en las asambleas y tomas de la universidad, los debates ideológicos con compañeros o sus reflexiones en torno a sus opciones partidarias, quienes hacían de la villa su ámbito de acción -ya sea como docentes, como trabajadores sociales o como activistas políticos- planteaban las realidades que vivían los niños en la escuela, las problemáticas de los vecinos y los interrogantes de cómo profundizar las propias prácticas en dichos escenarios ${ }^{23}$.

Más allá de las particularidades de cada ambiente, la reflexión semanal no excluía el abordaje de otros aspectos de la vida de los militantes, como los temas de la coyuntura histórica local, nacional o internacional ${ }^{24}$. Esto implicaba el análisis de un amplio abanico de cuestiones que iban desde los acontecimientos que sacudían a la opinión pública hasta problemas generales como la pobreza, las desigualdades sociales, la dependencia económica o incluso los debates sobre el aborto o la bioética, frente a los cuales se buscaba adoptar una postura crítica ${ }^{25}$.

22 Entrevista a José, Bahía Blanca, 19/6/2008. Integró la JOC (1970-1975), fue dirigente del grupo Scout "San Jorge" de Nuestra Señora del Carmen, y participó de reuniones del PB.

23 Entrevista a Marta, Bahía Blanca, 29/5/2008. Tuvo militancia social (como maestra) y política (JP) en Villa Nocito, en la primera mitad de la década de 1970.

24 "Historia de la JOC en Bahía Blanca", documento elaborado por Mirta, Jorge y un grupo juvenil del barrio de Grunbein a mediados de los '80. Archivo de Mirta y Jorge.

25 Entrevistas a Gustavo, 9/8/2012; a Pedro, Buenos Aires, 16/11/2012; a Ricardo, Bahía Blanca, 8/10/2011. Gustavo participó en el grupo Scout "San Jorge", donde llegó a ser dirigente, integró la JEC (1972 y 1974/5), militó en la UES y en la JP-Montoneros. Ricardo fue dirigente en el grupo Scout "San Pío X" de La Pequeña Obra, participó en la JEC, la UES y la JUP. Pedro fue dirigente de "San Pío X" e integrante de la JEC. 
En este marco, la política tenía un lugar privilegiado, se constituía en un problema cotidiano y su abordaje se planteaba con naturalidad, impregnando diversos temas ${ }^{26}$. Así, algunos hechos clave de esos años tomaron largos debates en los equipos de "revisión de vida". Entre ellos, el asesinato del ex presidente de facto Aramburu, perpetrado por la organización Montoneros el $1^{\circ}$ de junio de $1970^{27}$, la vuelta a la democracia y las elecciones de marzo de $1973^{28}$, la renuncia de Cámpora o la muerte de Perón.

Por último, en los equipos de reflexión se compartían las experiencias referidas a la vida cotidiana de los militantes, a sus relaciones familiares o de amistad y a sus problemas personales ${ }^{29}$. Al respecto, algunos actores ligaban el tratamiento de estos temas a la etapa particular que por entonces transitaban los jóvenes, la "salida" del propio hogar, y lo ubicaban en los primeros tiempos de los equipos, mientras asociaban los siguientes con el abordaje de las cuestiones referidas al mundo laboral o estudiantil ${ }^{30}$. Para otros, en cambio, la reflexión sobre la vida más íntima de los militantes, como las vicisitudes de la pareja o de la vinculación con los hijos, correspondió en la JUC a la última etapa, marcada por el recrudecimiento de la represión y la profundización de las prácticas políticas clandestinas, lo que conducía a evitar la discusión sobre las prácticas vinculadas a la militancia ${ }^{31}$.

26 Entrevistas a Carlos, Bahía Blanca, 4/5/2011; a Juan, 24/8/2011; a Pedro, Buenos Aires, 15/11/2012; a María, Bahía Blanca, 21/3/2013; a Manuel y Nancy, Neuquén, 21/3/2013; a María del Carmen, Bahía Blanca, 18/5/2011. Carlos participó en "San Pío X” entre 1961 y 1974, desde los 5 años hasta convertirse en dirigente, y fue integrante de la JEC (1972 y 1974). Juan, integró el grupo Scout "San Jorge" de niño, y participó en la JEC, de la UES y de la JTP (1972-1975). María integró la JUC (1968-1972), fue catequista, docente en barrios periféricos y participó del grupo estudiantil ligado al PB en la UNS. María del Carmen fue dirigente en el grupo Guía-Scout de La Pequeña Obra e integró la JEC entre 1972 y 1975.

27 Entrevista a Pablo, Neuquén, 19/3/2013; y a Nora, Bahía Blanca, 4/6/2008. Ambos fueron miembros de la JUC. Pablo fue militante de los Grupos Socialistas y del PRT-ERP. Nora tuvo militancia social y política en Villa Nocito entre 1968 y 1975.

28 Entrevista a Mónica, Buenos Aires, 9/11/2011. Entrevista a Juan, 31/5/2011.

29 Entrevistas a Nora, Bahía Blanca, 4/6/2008; a Carlos, Bahía Blanca, 4/5/2011; a Francisco, Buenos Aires, 16/11/2012. "Historia de la JOC en Bahía Blanca". Francisco participó de "San Pío X", de la JEC y de la UES.

30 Entrevista a Angélica, Bahía Blanca, 25/4/2012; y a Inés, Bahía Blanca, 18/6/2011. Angélica integró la JOC (1972 y 1975), fue catequista y participó de asambleas del sindicato Empleados de Comercio.

31 Entrevista a Nora y Rodolfo, Bahía Blanca, 2/4/2009. Entre 1970 y 1975 fue militante barrial, primero desde el PB y, a partir de 1973, desde las filas de la JP-Montoneros. 
Unos apuntes tomados por una joven de la JUC durante un campamento de verano de la rama universitaria celebrado en enero de 1970, nos permiten ilustrar el abanico de cuestiones que eran objeto de reflexión mediante la metodología de la "revisión de vida". En primer lugar, el grupo se proponía abordar la JUC y, concretamente, la integración de los equipos entre sí, a la comunidad y a la Iglesia. Luego, la atención se movía a la "realidad global 69", focalizándose en el movimiento estudiantil y su significación, el movimiento obrero y el proceso socioeconómico. En tercer lugar, reflexionaba sobre la vivencia cristiana de la JUC durante 1969, centrándose en la fe a nivel personal y en el equipo, en el medio y en relación a la liturgia. Por último, analizaba el compromiso de la JUC durante el año anterior, distinguiendo los planos personal y comunitario, así como los niveles de la "promoción humana", la "evangelización" y la "estructura". Le seguía la "interpretación profética", en la que se discriminaban el "esclarecimiento humano" y el "evangélico", y la interpretación evangélica del compromiso político. Las anotaciones siguientes aludían a algunos de los aspectos enunciados. Por ejemplo, mencionaban la diversidad de los centros o medios como aspecto negativo de la integración de los equipos, la falta de encuentro humano en un grupo que debía priorizar esa dimensión aún antes de la reflexión cristiana, la carencia de conocimiento de "la Palabra actualizada de Cristo hoy en la Iglesia" presente en Medellín y otros documentos, la ausencia de "clarificación evangélica", al tiempo que los jucistas se "manejaban con ideas muy generales", la ubicación de los militantes en un lugar de comodidad y "receptividad" dentro de los equipos y la inexistencia de la necesidad de explicitar el cristianismo ${ }^{32}$.

El abordaje de temas diversos mediante el método "Ver, Juzgar y Obrar" fue también una marca de experiencias que tuvieron lugar en otros lugares de América Latina. Así, los jocistas de Guatemala se ocupaban de problemas personales, laborales y comunitarios, abarcando múltiples cuestiones que iban desde el abuso sexual hasta el trabajo, la justicia o la educación (LEVENSON, 2007).

\section{Una nueva forma de vivir la fe}

Desde la perspectiva de los actores, su paso por la JUC, la JOC y la JEC significó el redescubrimiento -y aún el descubrimiento a secas- y la maduración de su fe. Para quienes participaban ya de la vida de la capilla Nuestra Señora del Carmen o de La Pequeña Obra, los equipos jucistas, jecistas y

32 Apuntes de una reunión de la JUC, durante un campamento de verano en la localidad balnearia de Pehuen-có, 16/1/1970. Archivo personal de Julio. 
jocistas marcaron una continuidad o una profundización de las novedades litúrgicas y teológicas que venían incorporando los sacerdotes "Pepe" y Emilio en dichos espacios. En efecto, estos presbíteros se constituyeron en referentes de esta nueva forma de ser cristianos, al igual que otros sacerdotes y religiosas identificados con el cristianismo liberacionista animadores de diversos grupos y espacios en Bahía Blanca y la vecina localidad de Punta Alta con los que estaban en contacto muchos militantes de los equipos de "revisión de vida"

Al mismo tiempo, las nuevas maneras de pensar y vivir el catolicismo se ubicaban en las antípodas de aquellas que los jóvenes habían conocido en los colegios religiosos, en el catecismo o en grupos laicales donde algunos de ellos habían iniciado su militancia católica, y que en no pocos casos habían puesto en crisis sus creencias y su pertenencia eclesial. En efecto, la inserción en espacios de acción social y política contestataria requería también una nueva experiencia espiritual, una nueva forma de vivir la oración personal y comunitaria (GUTIÉRREZ, 1971).

Por un lado, en contraste con los deberes que rodeaban la experiencia religiosa en el pasado, el grupo de reflexión se presentaba como un espacio abierto, que no requería una declaración previa de la identidad católica, y la integración a él como una opción personal, libre, voluntaria ${ }^{34}$. Por otro lado, se trataba de una fe que hacía sentido en la vida de cada uno. La lectura del Evangelio interpelaba a cada cual en su cotidianeidad y parecía tener algo que decirles. Al mismo tiempo, las celebraciones, compartidas en comunidad y donde todos construían la homilía, se cargaban de contenido ${ }^{35}$. En este proceso, lejos de aceptar verdades incuestionables, repetir las lecciones de los catequistas y sentirse espectadores de misas vacías, los laicos adquirían una real participación en las prácticas religiosas ${ }^{36}$. Asimismo, el ingreso a estas organizaciones cristianas juveniles les permitió conocer una nueva imagen de Dios, donde en lugar del castigo, prevalecía el amor, la misericordia y la cercanía. Desde la nueva perspectiva, los jóvenes podían encontrarlo en los momentos y situaciones ordinarias, en la vida de todos los días y en las "cosas sencillas" 37 .

33 Para un análisis de las redes sociales del catolicismo liberacionista en estas ciudades véase DOMINELLA, 2015.

34 Palabras de Jorge, Entrevista a Mirta y Jorge, Bahía Blanca, 14/7/2012.

35 Entrevista a Paloma, vía skype, 11/2/2013.

36 Entrevista a Inés, Bahía Blanca, 18/6/2011; a Julio, Bahía Blanca, 22/5/2010; a María, Bahía Blanca, 21/2/2013; a Elena, Bahía Blanca, 17/6/2010. Elena participó de la JUC y de la militancia en la UNS.

37 Entrevista a Pedro, Buenos Aires, 15/11/2012. 
En esta nueva experiencia de fe, los jóvenes comenzaron a renegar de las formalidades, a cuestionar a la institución, a distinguir la propuesta evangélica de las dinámicas eclesiales ${ }^{38}$. El centro de la misión cristiana era ahora el hombre, lo que acercaba a los militantes cristianos a los activistas no creyentes movidos por las mismas premisas. Juan destacaba este punto con una anécdota: "cuando fue la muerte del Che, por ejemplo, [Pepe] no dudaba de que iba a estar en el paraíso, $Y$ nos decía eso y lo fundamentaba por qué: por el compromiso con los pobres" $" 39$. Desde entonces, para los jóvenes el sentido de la fe católica era el amor al prójimo y el mandamiento de dar la vida por los hermanos ${ }^{40}$, lo que incluía las nociones de solidaridad y de servicio ${ }^{41}$. El amor a Dios ya no se manifestaba en la repetición de oraciones o el cumplimiento de ayunos y de la obligación de ir a la iglesia, sino en salir al encuentro de los hermanos.

Por otra parte, la nueva propuesta contemplaba la comunidad como instancia fundamental para la vivencia religiosa. La relación con Dios estaba mediada por los otros, se volvía necesariamente "social"42. En palabras de María: "babiamos llegado a la conclusión que la forma madura de vivir la fe y reflexionarla era a través de la comunidad"*3. En efecto, el testimonio de los compañeros y el acompañamiento del asesor apuntalaban la propia reflexión cristiana.

\section{El descubrimiento de "la realidad" y el impulso al compromiso}

La "revisión de vida" también significó para los actores la oportunidad para acercarse intelectualmente al escenario económico, político y social de su tiempo, desarrollar una mirada crítica sobre aquél y pensar el papel de cada uno en ella. Ahora bien, en cuanto la reflexión cristiana proponía un nuevo modo de vivir la fe que establecía un necesario "puente" con la realidad, los

38 Entrevista a Clara, Bahía Blanca, 10/10/2012. Jocista, fue catequista y participó de reuniones del $\mathrm{PB}$.

39 Entrevista a Juan, 31/5/2011.

40 Entrevista a José, Bahía Blanca, 19/6/2008; a Ana, Bahía Blanca, 17/10/2012; a Elsa, Bahía Blanca, 9/3/2012; a Norma, Bahía Blanca, 8/4/2011. Ana fue dirigente en el grupo Guía-Scout de La Pequeña Obra, desde 1970, e integró la JEC, desde 1972. Elsa fue jucista, militante de la JUP, la JP y Montoneros. Norma, se incorporó como dirigente al grupo Scout "San Pío X” en 1973 y participó de la JEC, en 1974.

41 Entrevista a Ana, Bahía Blanca, 17/10/2012; a Clara, Bahía Blanca, 10/10/2012; a José, Bahía Blanca, 19/6/2008; a Patricia, Bahía Blanca, 19/5/2008.

42 Entrevista a Ángel, Buenos Aires, 8/10/2009.

43 Entrevista a María, Bahía Blanca, 21/2/2013. 
actores encontraron en estos grupos un impulso para la acción ${ }^{44}$. Desde la óptica de los protagonistas, el compromiso cristiano "salía" de los intercambios y lecturas colectivas, esto es, era abrazado desde la reflexión comunitaria, debía trascender los muros de la iglesia para proyectarse en la sociedad y la política, y era precisamente lo que daba sentido a estos grupos cristianos. Como explica Levenson (2007), la JOC hacía énfasis en que la gente tenía el poder de transformar la vida. Al declarar a las masas como entes capaces de percibir la realidad, al proclamar su capacidad de ser jueces y actores, y al llevarlos junto con sus problemas concretos al seno de la Iglesia, la JOC creó una dinámica que a menudo llevó al activismo político, incluso mucho antes del advenimiento de la teología de la liberación ${ }^{46}$.

Ahora bien, ¿qué rasgos asumía el compromiso cristiano tal y como lo entendían los actores? En primer lugar, se orientaba hacia la transformación de la sociedad. "Hombre Nuevo", "mundo nuevo", "liberación" constituían el horizonte del compromiso cristiano. Esto aparecía como una exigencia desde el momento en que se consideraba, con la nueva teología latinoamericana, que era en ese proceso donde se daba la salvación cristiana. En palabras de Gutiérrez, "el hecho histórico, político liberador es crecimiento del Reino, es acontecer salvífico pero no es la llegada del Reino, ni toda la salvación” (1971: p. 228). Así, "la lucha por una sociedad justa se inscribe plenamente y por derecho propio en la historia salvífica" (1971: p. 216). Por otra parte, esta empresa aparecía como posible e inminente.

44 Entrevista a Roberto, Bahía Blanca, 18/4/2013; a María, Bahía Blanca, 21/2/2013; a Héctor, Bahía Blanca, 1/5/2010; a Elena, Bahía Blanca, 17/6/2010; a Julio, Bahía Blanca, 22/5/2010; a Ángel, Buenos Aires, 8/10/2009; a Nora, Bahía Blanca, 4/6/2008; a Juan Carlos, Buenos Aires, 1/8/2008; Mónica, Buenos Aires, 30/7/2008; a Mario, Bahía Blanca, 5/1/2013; a Francisco, Buenos Aires, 16/11/2012; a Juan, Bahía Blanca, 31/5/2011; a Noma, Bahía Blanca, 8/4/2011; a Inés, Bahía Blanca, 18/6/2011; a Alicia, Bahía Blanca, 9/7/2011. Roberto integró la JUC (1968-1972), militó en la agrupación del PB en la UNS y luego en la JP. Héctor integró la JUC y fue militante del Frente Estudiantil Nacional y del PB. Juan Carlos, entre 1968 y 1974 militó en diversas agrupaciones universitarias: AUDAL, Grupos Socialistas y JUP; luego, trabajó en el SLA. Mario participó en "San Pío X" desde niño, y tuvo un breve paso por la JEC.

45 Entrevista a Alicia, Bahía Blanca, 9/7/2011. En 1972 y 1973 participó de la JEC, y durante este último año, militó en la UES.

46 Así, la JOC jugó un papel importante en la vida de la clase obrera en muchas ciudades. De la rama de Buenos Aires, por ejemplo, creció la Confederación Sindical Continental Demócrata Cristiana, de tendencia centrista, la Confederación Latinoamericana de Trabajadores (CLAT) y en Brasil, los militares abolieron las JOC en 1964 porque sus miembros eran militantes sindicales (LEVENSON, 2007). 
Ese compromiso se traducía en lo que más tarde se consagraría como la "opción por los pobres", lo que suponía una toma de posición frente al conflicto entre clases sociales. En este sentido, Nora explicaba que lo que estaba en juego era "desde qué lugar nos ubicábamos para mirar la sociedad y su transformación" ${ }^{47}$. Desde esta perspectiva, era prioritario ayudar y cambiar la situación de las personas desvalidas/desposeídas/negadas en su dignidad, que tenían sus necesidades básicas insatisfechas, que sufrían la desocupación, la inestabilidad laboral, la precariedad de la vivienda, las dificultades para acceder a la educación, etc. Si bien no se descartaba la asistencia directa, era fundamental priorizar las acciones orientadas a su promoción o, en palabras de José, procurar que "se sepan defender" por sí mismos.

Por otra parte, la profundización del compromiso suponía traducir las enseñanzas bíblicas a las actitudes y comportamientos ordinarios. Seguir el ejemplo de Jesucristo significaba asumir un estilo de vida marcado por la búsqueda de coherencia personal. En primer lugar, se hacía hincapié en la austeridad, así como en el rechazo a la ostentación y al consumismo. Hacerse pobre como lo hizo Jesús suponía "no estar a la última moda", "no tentarse con los placeres mundanos"49, "andar con lo puesto"

Además, el énfasis en la responsabilidad y el trabajo acompañaba la formación de los jóvenes en estos espacios. La exigencia, la disciplina personal, el estar "siempre listos" -según rezaba el lema Scout- atravesaban sus prácticas. En el marco de una dinámica grupal que implicaba un compromiso con los otros, los jóvenes se auto-imponían las obligaciones y no se permitían llegar tarde, faltar, involucrarse a medias, distraerse o, en palabras de Paloma, "aflojar" recreación quedaban relegados a un lugar marginal en la cotidianeidad de los militantes o bien se distanciaban de aquellos generalmente transitados por la juventud de la época. Desde la lógica de los actores, hábitos como salir a bailar o ir al cine eran pensados como actitudes superficiales/ individualistas o bien como una suerte de lujo innecesario.

Ser buen hijo, buen hermano, buen amigo, buen esposo, buen vecino, buen compañero, buen alumno, buen Scout, etc. implicaba también, que esos

\footnotetext{
47 Entrevista a Nora, Bahía Blanca, 4/6/2008.

48 Entrevista a José, Bahía Blanca, 19/6/2008.

49 Entrevista a Juan, 31/5/2011 y Bahía Blanca, 14/8/2012.

50 Entrevista a Pedro, Buenos Aires, 15/11/2012.

51 Entrevista a Paloma, vía skype, 11/2/2013.
} 
vínculos estuvieran regidos por el respeto, la honestidad y la valorización de la persona. La búsqueda de coherencia llevaba a cuestionar, incluso, las actitudes que los compañeros, tanto de los grupos cristianos como de los políticos, tomaban en su vida privada. En este sentido, Eduardo recordaba una discusión con un militante a propósito de sus conductas sexuales:

Le digo: lindo ejemplo el tuyo, haciendo uso de una mujer, por placer nada más, no porque la quieras $[\ldots]$ ¿cuál es el tipo de revolucionario que vos estás proponiendo? [...] ¿Es un revolucionario que va a ser capaz de utilizar a otros en beneficio propio? ¿ $\mathrm{O}$ va a ser capaz de dignificar a otros dándole espacio y respetándolos? ${ }^{32}$.

Se trataba de dar forma, a partir de la propia vida, al Hombre Nuevo; de asumir sus valores éticos y morales durante la construcción misma de un orden social más justo, orden que acabaría por consagrarlo, bajo la forma de mujeres y hombres comprometidos, generosos, sencillos, al servicio de los demás, sinceros, auténticos, leales, disciplinados. Como afirma Carnovale, el Hombre Nuevo era mucho más que un portador de la ideología revolucionaria: era la encarnación de la nueva era, de nuevos valores, de nuevas sensibilidades, de una nueva moral. Y esa nueva moral se construía, se templaba y se evidenciaba en el día a día, en cada acto, en cada decisión; de ahí la necesidad de la prescripción y de la vigilancia permanente de la conducta cotidiana (2012: p. 84). Este ideal se constituía, de este modo, en el modelo a seguir no sólo en las organizaciones político-militares sino también al interior de las redes católicas liberacionistas. Por otra parte, las virtudes del Hombre Nuevo, encarnado en la figura del Che Guevara, tenían claras resonancias cristianas. De allí que, esta matriz de valores y actitudes personales aprendidas en los grupos cristianos, encontró más tarde afinidades con las que regían la vida del militante en las agrupaciones políticas. Cuando los jucistas, jocistas y jecistas se incorporaron al activismo contestatario, contaban con una formación ética y moral que aportaron al nuevo espacio, o bien que les permitió trabajar sobre una misma base con los compañeros que tenían otras trayectorias previas.

La experiencia de la "revisión de la vida" también daba cuenta de que el compromiso era un asunto colectivo. El mismo proceso de lectura crítica de la realidad y de toma de postura a favor de la "liberación de los oprimidos" no era transitado en soledad sino junto a los compañeros y amigos. La militancia

52 Entrevista a Eduardo, Bahía Blanca, 20/5/2008. 
aparecía a la vez como elección personal y como fruto de una formación y de, en palabras de Juan, un “crecimiento” grupal. Además, el equipo de reflexión era el sostén para la acción social y política de los militantes. Los intercambios con los pares eran centrales para repensar continuamente la propia práctica y potenciarla. Los compañeros se convertían en referentes para clarificar los objetivos y fundamentos de la militancia, y buscar su "coherencia" con los valores cristianos. Asimismo, para los creyentes, la fe que se compartía en sus comunidades, alimentaba y consolidaba sus opciones de militancia. Al decir de Paloma cuando evocaba las homilías compartidas: "esa experiencia hacía que ese compromiso creciera, se hiciera más explícito, tuviese más sentido" "53.

En otras palabras, la convicción de que la relación con Dios se daba en el encuentro con los otros y la vivencia de comunidad fueron claves en la gestación de una concepción de lo colectivo como condición fundamental de la construcción social y política. La propia experiencia mostraba que la generación de proyectos alternativos requería el trabajo en común, el compartir con el otro e integrarse a un grupo ${ }^{54}$. Como afirma Mallimaci, los militantes de la Acción Católica compartían el sentimiento de ser responsable del otro, la idea de que los hombres son dependientes entre sí, que la solidaridad grupal debe primar al "egoísmo individualista" y que nadie se "salva solo" sino que lo hace en grupo y comunidad (2015, p. 106).

En este sentido, los grupos de "revisión de vida" también actuaron como puntapié para el compromiso social y político de los militantes cristianos a partir de las relaciones afectivas tejidas en ellos. Al interior de estos círculos sociales, como señala González Bernaldo de Quirós (2008) para otros referentes empíricos, la dimensión emocional se constituyó en un componente fundamental de los vínculos, en tanto éstos se alimentaban de visiones del mundo y valores compartidos, de una interacción cotidiana, regular e intensa y de actividades comunes que en sí mismas implicaban, en muchos casos, un involucramiento personal y afectivo. Al mismo tiempo, el contexto grupal actuó como estructura de contención y las relaciones interpersonales allí tejidas sirvieron como marco para la construcción y el mantenimiento de una identidad colectiva (DEAUX y MARTIN, 2003). Así, la pertenencia a la JUC, a la JEC y a la JOC, se erigió en un elemento constitutivo fundamental de la identidad de este conjunto de militantes. El hecho de compartir una determinada forma de vivir la fe, un estilo de vida marcado por el compro-

\footnotetext{
53 Entrevista a Paloma, vía skype, 22/2/2013.

54 Entrevista a Paloma, vía skype, 1/3/2013.
} 
miso y la austeridad, un conjunto de ideas vinculadas a la transformación de la sociedad, diversas prácticas sociales y políticas concretas, un ámbito de reflexión sobre esa inserción en la realidad, y espacios celebratorios, sellaron relaciones afectivas profundas y duraderas. Tal como plantea Guglielmucci para las organizaciones revolucionarias: "constituía un colectivo surcado por relaciones no sólo políticas, sino también de parentesco, amistad y pareja", "la organización conformaba para sus miembros un referente político y afectivo primordial" (2006, p. 76-77). En consecuencia, la afectividad fue un elemento esencial en las prácticas colectivas, dentro del espacio eclesial y más allá de éste, y en las decisiones personales de los militantes en lo referente a su participación eclesial y en la asunción de alguna forma de acción en la sociedad o la política.

El compromiso cristiano implicaba, al mismo tiempo, la crítica al orden vigente y el anuncio de otro mundo posible; esto es, por un lado, la denuncia explícita de las injusticias y de sus causas, y, por el otro, una acción concreta y eficaz para erradicarlas ${ }^{55}$. En Medellín, los obispos latinoamericanos habían planteado que le correspondía a la Iglesia denunciar con firmeza las realidades que constituían una afrenta al espíritu del Evangelio. Por su parte, el MSTM ${ }^{56}$ trazaba el modelo del profeta como crítico de la sociedad (MARTÍN, 2010): de cara al proceso de liberación, la Iglesia debía denunciar las injusticias y juzgar los programas políticos o económicos a la luz de la Palabra de Dios ${ }^{57}$. En consecuencia, por medio de comunicados, en general repartidos bajo la forma de volantes (a la salida de las misas dominicales en distintas iglesias de la ciudad, en las instituciones de educación superior y en los barrios), o en ocasiones publicados como cartas o solicitadas en la prensa local o nacional, o bien leídos en conferencias de prensa, estos grupos expresaron sus críticas contra acciones y medidas de la "Revolución Argentina" 58 , de las fuerzas armadas y de seguridad, de las autoridades municipales o de La Nueva Provincia".

55 Entrevista a José, Bahía Blanca, 19/6/2011. "Por qué de mi militancia en la JOC", apuntes de Paloma, enviados vía e-mail, febrero de 2013.

56 Comenzó a estructurarse en 1968 a partir de la adhesión de sacerdotes de distintos puntos del país al Manifiesto de 18 obispos del Tercer Mundo. Reunió a más de 500 presbíteros, que constituían el $9 \%$ del clero, eran predominantemente diocesanos y al menos un tercio se había formado durante el Concilio Vaticano II (MARTíN, 2010).

57 Nuestra Reflexión, 11/10/1970, en: BRESCI, 1994.

58 Dictadura militar instaurada con el golpe de Estado de junio de 1966, se extendió hasta 1973 bajo las presidencias de facto de Juan Carlos Onganía, Roberto Levingston y Alejandro Lanusse.

59 Diario bahiense fundado en 1898 por Enrique Julio y propiedad de la familia Massot. La empresa fue ampliada con la adquisición, en 1958, de LU2 Radio Bahía Blanca y, en 1965, 
Los textos firmados por las ramas especializadas de Acción Católica y otros grupos laicales, se desarrollaban al ritmo del "Ver, Juzgar y Obrar", de modo que incluían la descripción y análisis de un problema del entorno, su interpretación a la luz de la Biblia y los documentos de la Iglesia o sus referentes, y una propuesta de intervención o toma de postura "como cristianos" que se desprendía de lo anterior.

La emisión de documentos de denuncia en los que a partir de la condena de situaciones concretas, se impugnaba el orden social y político existente era una estrategia común a las distintas expresiones de la renovación eclesial (DONATELLO, 2010). Los estudiantes católicos de otros lugares del mundo también echaron mano a las declaraciones para expresar sus posicionamientos ante determinados acontecimientos sociales y políticos ${ }^{60}$. En el orden nacional, los comunicados sobre diversos hechos políticos fueron una forma típica que marcó las intervenciones públicas del MSTM, aunque su participación se extendió, además, a distintos actos de protesta, ayunos, ollas populares, ocupaciones de fábricas e ingenios y notas en los medios de comunicación (TOURIS, 2012).

En cuanto al "anuncio" de otro mundo posible, como plantea Donatello, desde el catolicismo liberacionista, se construyeron diversas opciones políticoreligiosas, a través de las cuales los militantes desarrollaron su ascesis política. Para aquellos que querían proseguir su acción fuera del campo religioso, esto suponía elegir entre un abanico de alternativas que iban desde la participación en ámbitos sindicales, hasta la incursión en la política insurreccional (2005a: p. 85-86). Así, en el caso de la JUC, podemos reconocer diferentes perfiles y espacios de militancia ${ }^{61}$ : estudiantil (la universidad), barrial (especialmente, en Villa Nocito, a partir del trabajo en la escuela Nuestra Señora de la Paz ${ }^{62}$ o en la Unidad Básica peronista), eclesial (como dirigentes scouts o guías, y

de Canal 9 Telenueva, convirtiéndose en la voz periodística hegemónica en la ciudad. Durante esos años, mantuvo un discurso antiperonista, antitercermundista y pro-militar. En la actualidad, su director, Vicente Massot, se encuentra acusado por crímenes de lesa humanidad (ZAPATA, 2008).

${ }^{60}$ Véase, por ejemplo, "Declaración común de la JEC y la Acción Católica Universitaria francesas", JEC Boletín Secundario, 8, noviembre de 1968.

61 Para un mayor desarrollo de este tema véase DOMINELLA, 2010.

62 Perteneciente a Cáritas, fue inaugurada en marzo de 1971. Fue dirigida por la hermana Norma Gorriarán hasta marzo de 1975 -momento en el que debió exiliarse-. Pronto se constituyó en un centro de referencia educativo, eclesial y comunitario para la gente del barrio. Los domingos se celebraba misa en el pasillo. Diariamente, se ofrecía la merienda, y por las noches, funcionaba un Centro de Educación de Adultos. 
referentes del MIEC-JECI), sindical, social, política. Esta última se canalizó en diversas organizaciones de la izquierda peronista y no peronista. En el caso de la JOC, los espacios de acción eran: la parroquia, donde buena parte participaba en la liturgia, la catequesis o los scouts, logrando así una inserción pastoral quizás mayor que las otras ramas especializadas; el lugar de trabajo y el gremio, donde se intentaba "concientizar" a los compañeros sobre sus derechos y la lucha por mejores condiciones de trabajo; y el PB. Los militantes de la JEC, por su parte, también encarnaron su compromiso cristiano en múltiples espacios, tanto eclesiales como sociales y políticos: fueron dirigentes del movimiento scout-guía, catequistas, coordinadores de nuevos equipos de JEC, colaboradores de diversas actividades sociales en barrios periféricos, voluntarios de Cáritas ${ }^{63}$ o activistas políticos de la UES y/o de Montoneros.

Destacar el impulso al compromiso dado desde la JUC, JOC y JEC no implica negar la importancia que en las trayectorias militantes de estos actores tuvieron previa o contemporáneamente otros grupos y referentes del catolicismo liberacionista, con la que ellos entraron en contacto tanto a nivel local como nacional. Entre ellos, el movimiento Guía-Scout, Cáritas, el MSTM o los Campamentos Universitarios de Trabajo ${ }^{64}$.

Tampoco supone desconocer la impronta que en sus opciones dejaron experiencias ajenas al ámbito eclesial, como las iniciativas de ayuda a los sectores marginados emprendidas desde los ámbitos educativos donde se formaron, o los principios y prácticas que mamaron en sus casas. Como afirma Levenson (2007), en la ciudad de Guatemala, la vida en los barrios y la familia dieron a los futuros sindicalistas valores y experiencias en la solidaridad. En relación a los bahienses, la fe, las inquietudes/el compromiso social o la actitud crítica

63 Había comenzado a funcionar en 1969, teniendo como director al padre Néstor Navarro. La institución se centró en la ayuda inmediata, aunque con una mirada promocional, dando forma a distintas iniciativas, como el equipo de Trabajadores Sociales, los servicios jurídico, de farmacia, y de alimento y ropa, los grupos que trabajaban en centros de salud y un comedor popular. Para obtener recursos económicos, compró un mimeógrafo para vender apuntes a los estudiantes. Toda la actividad se acompañaba con reuniones de revisión de la tarea y de oración, en las que se compartían lecturas evangélicas y de documentos eclesiales. Surgidos como iniciativa del jesuita José María Llorens, en el barrio San Martín de Mendoza en 1964, proponían la inmersión de los universitarios de todo el país, cristianos y no cristianos, en el mundo de los marginados -fundamentalmente, los trabajadores rurales de regiones del interior -, con los que compartían sus condiciones de vida y de trabajo durante un mes del verano. De esta experiencia participaron vario jucistas bahienses y "Pepe" Zamorano. "Campamento Universitario de Trabajo", volante s/f (hacia 1966), Archivo personal de Julio. 
de sus padres y abuelos, y el ejercicio de discusión política en la mesa, fueron preparando el camino para su propio acercamiento a la sociedad y a la política. En este sentido, Nora decía: "no naci de un repollo tampoco ¿no? (sonrie), digamos, esta sensibilidad por lo social y eso la recibi de mi papá",5, quien había participado de las luchas de los maquinistas en el gremio "La Fraternidad" y de la organización de su pueblo a la vera de las vías del tren, al sureste de la provincia de Buenos Aires.

\section{Reflexiones finales: las implicancias políticas de "Ver, Juzgar y Actuar"}

A partir de lo analizado, podemos decir que, en gran medida, estos jóvenes descubrieron la acción social y política desde la JUC, la JEC y la JOC, en el marco de las redes del catolicismo liberacionista de la ciudad y el país, y que las prácticas que asumieron como consecuencia encontraron impulso y justificación en una determinada visión de la fe, encarnada/comprometida con la realidad. En otras palabras, los jucistas, jocistas y jecistas fueron recorriendo un camino que marcó un trayecto militante que desde el compromiso cristiano los habría de llevar a asumir diversas formas de intervención en una serie de espacios sociales y políticos. Más allá de los antecedentes familiares o escolares, el comienzo de dicho recorrido se encuentra precisamente en esta instancia de "descubrimiento" y "reflexión" de la vida personal desde una perspectiva del cristianismo, que representaron los movimientos especializados de juventud.

En efecto, la "revisión de vida" tenía implicancias significativas. En primer lugar, planteaba una novedad en la articulación de la escritura y el dogma. El punto de partida de la hermenéutica bíblica eran "los hechos y preguntas recibidos del mundo de la historia” (GUTIÉRREZ, 1971, p. 29), y no la revelación como dato o un conjunto de verdades que debían ser llevadas a la acción. Como ha analizado Mallimaci (1992, 2015), se partía de la realidad misma, donde los militantes buscaban cómo llevar adelante su apostolado. Esto significa que la doctrina católica era releída a partir de la militancia en un contexto cultural, subjetivo, histórico, religioso particular y que la prioridad residía en el análisis de las problemáticas específicas del medio de acción por los militantes, antes que en las directivas de la institución. En este marco, la lectura comentada de la Biblia era central, pues se entendía que la acción surgía tanto de la vida de Jesús como de sus continuadores en la construcción del

$\overline{65}$ Entrevista a Nora, Bahía Blanca, 4/6/2008. 
Reino de Dios, de modo que no existía una verdad única y eterna ni estaba reservada a la institución, sino que se construía con la participación de los militantes católicos.

En segundo lugar, el "Ver, Juzgar y Actuar" implicaba una forma particular de relación con Dios. Esta reflexión suponía un encuentro con la divinidad en una realidad históricamente situada, con lo cual "no hay posibilidad de evasión" Desde esta perspectiva, era en el "Actuar", en gestos concretos hacia el prójimo, en el encuentro con otros hombres, en el compromiso con el devenir histórico de la humanidad donde el cristiano amaba a Dios (GUTIÉRREZ, 1971). Así lo expresaba la JUC en una declaración de julio de 1971: "en la medida en que como cristianos no nos comprometemos, detenemos la historia y perdemos a Dios, que actúa en ella" ${ }^{\prime 67}$. Para estos movimientos juveniles, fe y compromiso estaban estrechamente vinculadas; y el culto sólo tenía sentido si estaba inserto dentro del "compromiso del hombre con el hombre" 68 .

Esto tenía profundas implicancias políticas, desde el momento en que el prójimo era el hombre considerado en la urdimbre de las relaciones sociales, el pueblo explotado, por lo cual, "dar de comer y de beber" como mandaba Jesús, era un acto político, exigía la transformación de esta sociedad (GUTIÉRREZ, 1971). Como sintetizaba una nota del Boletín Spes: amor a Dios es amor al hermano y amor al hermano es decir amor al oprimido y eso significa liberarlo ${ }^{69}$. Y en el mismo sentido, Dom Helder Camara, referente de esto militantes, se preguntaba "¿cómo hacer evangelización queriendo que el pueblo sufra con paciencia en esta vida, aguardando la recompensa del cielo, cuando esto sería transformar la religión en opio del pueblo, como afirma de ella el marxismo?"70. De allí, que a la afirmación jucista anterior le siguiera la interpelación: "a todos los

66 Entrevista a José Zamorano, Moreno, 19/9/2009.

67 "Militante cristiano secuestrado y torturado en Punta Alta". Cristianismo y Revolución, 30, septiembre de 1971. Esta revista sirvió de nexo al catolicismo liberacionista en Argentina. Fue publicada entre 1966 y 1971, bajo la dirección de Juan García Elorrio (hasta enero de 1970) y luego, de Casiana Ahumada. Fue un órgano de oposición al gobierno de Onganía. De su contenido sobresalen la difusión del pensamiento "post-conciliar", el apoyo al peronismo revolucionario y la defensa de la lucha armada como vía para la toma del poder y respuesta a la "violencia institucionalizada" del sistema (MORELLO, 2003).

68 "Notas sobre fe y compromiso", JEC Boletin Secundario, 9, abril de 1969. "Culto y compromiso. Ficha bíblica 8", Spes, 26, septiembre de 1975.

69 “El amor cristiano: ¿imperativo hoy?”, Spes, 12, noviembre de 1970.

70 "Iglesia que yo quiero. Dom Helder Camara", Spes, 22-23, enero de 1974. 
cristianos y hombres de buena voluntad [...] a solidarizarse en la búsqueda de una sociedad nueva" ${ }^{71}$.

En tercer lugar, la "revisión de vida" asumía una concepción integral de la vivencia de la fe que no se limitaba a la esfera de las creencias sino que expandía su influencia a toda la vida del militante, que debía ser guiada por los principios religiosos (GIMÉNEZ BÉLIVEAU, 2005, p. 221). Así, "Ver, Juzgar y Actuar" constituyó una metodología al servicio de un catolicismo integral que vinculaba la creencia religiosa y la vida personal con la vida social y política. Como explicaba Rodolfo, se insistía en

que la fe no se viviera como algo al costado o separado o sobreañadido a la vida. La fe y la Palabra de Dios como que eran en diálogo permanente con las prácticas, la vida, en todo sentido, no sólo la militancia política sino la vida de pareja, la relación de trabajo... ${ }^{72}$.

Por otro lado, este catolicismo vivido "integralmente" debía penetrar en cada uno de los "ambientes" donde los militantes desarrollaban su compromiso. En este sentido, la concepción que guiaba su acción era la del "fermento en la masa", que implicaba la inserción en la realidad con un estilo propio, esto es, animados por la fe y compartiendo una intensa vida en comunidad, pero sin segregarse de los demás hombres ${ }^{73}$. De esta manera, el compromiso por el cambio de la sociedad no podía afrontarse en soledad sino con otros. Como buenos católicos integrales, los jucistas, jocistas y jecistas también preferían sumarse a las iniciativas sociales, gremiales, políticas existentes, junto a otros hombres y mujeres.

En efecto, estos jóvenes eran "hijos de su tiempo", por lo que compartían las características de su generación. De allí, que la renovación eclesial

71 "Militante cristiano secuestrado y torturado...". Cristianismo y Revolución, 30, septiembre de 1971. En efecto, qué se veía, qué juicios se emitían y qué acciones se tomaban dependían de la sociedad y la época. Así, por ejemplo, como afirma Levenson (2007) para el caso de la JOC guatemalteca en los años sesenta, el resultado fue el sindicalismo, una lucha contra los patrones y después, inevitablemente, contra el Estado, en un contexto de terrorismo estatal y creciente pobreza de la clase trabajadora.

72 Entrevista a Nora y Rodolfo, Bahía Blanca, 2/4/2009.

73 En esta línea, por ejemplo, un encuentro de laicos realizado en Buenos Aires, en 1966, justificaba la exigencia de trabajar junto a los no cristianos en el "cambio de estructuras", desde una manera de entender y vivir el catolicismo propiamente "integralista": "no admitimos partidos ni colegios que sean para cristianos solamente. Queremos que los cristianos se mezclen con todos y actúen entre todos" (HABEGGER, 1970, p. 169). 
y su catolicismo integral no sean suficientes para explicar su pensamiento y práctica antisistémica. Ellos mismos se reconocían formando parte de un colectivo mucho más amplio y diverso de jóvenes que optaban por un proyecto social alternativo, a partir del rechazo a la dictadura de Onganía-LevingstonLanusse, del clima de movilización que generó su oposición, del modelo de la Revolución Cubana y los movimientos de liberación del Tercer Mundo; el ejemplo de los "mártires" latinoamericanos "Che” Guevara o Camilo Torres; la referencia a Perón y su esposa "Evita" en nuestro país; la lectura y discusión de los textos de Karl Marx, Marta Harnecker, Juan José Hernández Arregui, John William Cooke, Eduardo Galeano, Franz Fanon o las teorías de la dependencia; la identificación con prácticas culturales que alimentaban el clima de época. Sin embargo, como sintetizaba Mónica, los jucistas, jocistas y jecistas se sumaron a la "ola" de la acción social y política contestataria "entrando por ese costado", esto es, al ritmo de "Ver, Juzgar y Actuar" en la JUC, la JEC y la JOC, mientras sus compañeros de militancia lo hicieron a partir de trayectorias religiosas, ideológicas y políticas divergentes.

\section{Referencias}

BOFF, C. Epistemología y método de la teología de la liberación. En: ELLACURÍA, I. et al., Mysterium Liberationis: conceptos fundamentales de la teología de la liberación. Madrid: Editorial Trotta, 1990.

BRESCI, D. Movimiento de Sacerdotes para el Tercer Mundo: documentos para la memoria histórica. Buenos Aires: Centro Salesiano de Estudios San Juan Bosco, Centro Nazaret, Comisión de Estudios de Historia de la Iglesia en Latinoamérica (CEHILA), 1994.

DEAUX, K. y MARTIN, D. Interpersonal networks and social categories: specifying levels of context in identity processes. Social Psychology Quarterly, Volumen 66, n. 2, p. 101-117, 2003.

DOMINELLA, V. Espacios y prácticas de la militancia católica en Bahía Blanca (Argentina) a fines de los '60 y principios de los '70. Ánfora, Año 17, n. 29, p. 29-44, 2010.

DOMINELLA, V. Espacios de sociabilidad, redes sociales de la renovación católica y militancia contestataria en Bahía Blanca (Argentina), entre 1968 y 1975. Revista Cultura y Religión, vol. IX, nro. 1, p. 102-128, 2015. Disponible en: www.revistaculturavreligion.cl/index.php/ culturayreligion/article/download/593. Acceso: 15 de enero de 2017.

DONATELLO, L. Catolicismo y Montoneros: religión, política y desencanto. Buenos Aires: Manantial, 2010

DONATELLO, L. y CATOGGIO, S. Sociabilidades católicas y carreras militantes. Lucha Armada en la Argentina, Anuario 2010, p. 148-155, 2010.

74 Entrevista a Mónica, Buenos Aires, 30/7/2008. 
GIMÉNEZ, M. J. Ciudad de "Perros": historias de militancia y recorridos del PRT-ERP por la ciudad de Bahía Blanca. 2008. 142 p. Tesis (Licenciatura en Historia) - Departamento de Humanidades, Universidad Nacional del Sur, Bahía Blanca.

GIMÉNEZ BÉLIVEAU, V. Sociabilidades de los laicos en el catolicismo en la Argentina. Un recorrido socio-histórico. Prismas. Revista de Historia Intelectual, n. 9, p. 217-227, 2005.

GONZÁLEZ BERNALDO DE QUIRÓS, P. La “sociabilidad” y la historia política. Mundo Mundos Nuevos, 2008. Disponible en: http://nuevomundo.revues.org/24082. Acceso: 19 de abril de 2012.

GORDILLO, M. Protesta, rebelión y movilización: de la resistencia a la lucha armada. En: JAMES, D. (comp.) Violencia, proscripción y autoritarismo (1955-1976). Buenos Aires: Editorial Sudamericana, 2003.

GUGLIELMUCCI, A. Dar la vida y la muerte por la revolución. Moral y política en la praxis militante. Lucha Armada en la Argentina, n. 5, p. 72-91, 2006.

GUTIÉRREZ, G. Teología de la liberación: perspectivas. Lima: Editorial universitaria, CEP, 1971.

HABEGGER, N. Apuntes para una historia. En: MAYOL, A., HABEGGER, N. y ARMADA, A., Los católicos posconciliares en la Argentina. Buenos Aires: Editorial Galerna, 1970.

LEVENSON, D. Sindicalistas contra el terror: ciudad de Guatemala, 1954-1985. Guatemala: AVANCSO, 2007.

LÖWY, M. Guerra de dioses: religión y Política en América Latina. México: Siglo XXI Editores, 1999.

MALLIMACI, F. El catolicismo argentino desde el liberalismo integral a la hegemonía militar. En: AA.VV., 500 años de cristianismo en Argentina. Buenos Aires: CEHILA-Centro Nueva Tierra, 1992.

MALLIMACI, F. E1 mito de la Argentina laica: catolicismo, política y Estado. Buenos Aires: Capital Intelectual, 2015.

MALLIMACI, F., CUCCHETTI, H. y DONATELLO, L. Caminos sinuosos: nacionalismo y catolicismo en la Argentina Contemporánea. En: COLOM, F. y RIVERO, A. (edit) El altar y el trono: ensayos sobre el catolicismo político latinoamericano. Barcelona: ANTROPHOS/ UNIBIBLOS, 2006.

MARTÍN, J. P. El Movimiento de Sacerdotes para el Tercer Mundo: un debate argentino. Los Polvorines: Universidad Nacional de General Sarmiento, 2010.

MONTERO GARCÍA, F. La Iglesia y el catolicismo en el final del franquismo. El "despegue" de la Iglesia en la pretransición. 1960-1975. En: MATEOS LÓPEZ, A. y HERRERÍN LÓPEZ, A. (coord.) La España del presente: de la dictadura a la democracia. España: Asociación Historiadores del Presente, 2006.

MORELLO, G. Cristianismo y Revolución: los orígenes intelectuales de la guerrilla argentina. Córdoba: Universidad Católica de Córdoba, 2003. 
SCANONNE, J. C. La teología de la liberación. Caracterización, corrientes, etapas. En: Teología de la liberación y Doctrina social de la Iglesia. Madrid-Buenos Aires: Ediciones Cristiandad-Editorial Guadalupe, 1987.

SEOANE, M. Todo o nada. Buenos Aires: Planeta, 1993.

TOURIS, C. Profecía, Política y clericalismo popular en el Movimiento de Sacerdotes para el Tercer Mundo (MSTM): 1967-1973. PROHAL MONOGRÁFICO, Revista del Programa de Historia de América Latina, Vol. 3, Primera Sección: Vitral Monográfico, n. 3, p. 251$283,2012$.

ZAPATA, B. Páginas Manchadas: conflictividad laboral entre los gráficos y La Nueva Provincia en vísperas de la dictadura de 1976. 2008. 82 p. Tesis (Licenciatura en Historia) - Departamento e Humanidades, Universidad Nacional del Sur, Bahía Blanca.

Submetido em: 26-5-2017

Aceito em: 12-8-2018 